\title{
Targeting ErbB3-mediated stromal-epithelial interactions in pancreatic ductal adenocarcinoma
}

\author{
JS Liles', JP Arnoletti*,', AV Kossenkov², A Mikhaylina', AR Frost ${ }^{3}$, P Kulesza $^{4}$, MJ Heslin' and A Frolov' \\ 'Department of Surgery, University of Alabama at Birmingham, Birmingham, AL 35294, USA; '2Systems Biology Division, The Wistar Institute, \\ Philadelphia, PA, USA; ${ }^{3}$ Department of Pathology, University of Alabama at Birmingham, Birmingham, AL 35294, USA; ${ }^{4}$ Department of Pathology, \\ Northwestern University, Chicago, IL, USA
}

\begin{abstract}
BACKGROUND: We sought to investigate the role of ErbB3-mediated signalling on the interaction between pancreatic cancerassociated fibroblasts (CAF) and carcinoma cells in an effort to disrupt tumourigenic pancreatic ductal adenocarcinoma (PDAC) stromal-epithelial cross-communication.

METHODS: Primary CAF cultures were established from human PDAC surgical specimens. AsPC-I pancreatic cancer cell murine subcutaneous xenografts were developed in the presence and absence of CAF and were subsequently treated with epidermal growth factor receptor (EGFR) inhibitors (erlotinib) and ErbB3 inhibitors (MM-121, monoclonal ErbB3 antibody).

RESULTS: Cancer-associated fibroblasts were found to secrete neuregulin-I (NRG-I), which promoted proliferation via phosphorylation of ErbB3 and AKT in AsPC-I PDAC cells. This signalling cascade was effectively inhibited both in vitro and in vivo by specific ErbB3 blockade with MM-I2I, with greater degree of tumourigenesis inhibition when combined with erlotinib. The CAFAsPC-I pancreatic cancer xenografts reached significantly greater tumour volume than those xenografts lacking CAF and were resistant to the anti-tumour effects of EGFR inhibition with erlotinib.

CONCLUSION: Cancer-associated fibroblasts-derived NRG-I promote PDAC tumourigenesis via ErbB3-AKT signalling and overcomes single-agent EGFR inhibition. Disruption of this stromally mediated tumourigenic mechanism is best obtained through combined EGFR-ErbB3 inhibition with both erlotinib and MM- I21. We have identified the NRG-I/ErbB3 axis as an attractive molecular target for the interruption of tumourigenic stromal-epithelial interactions within the PDAC microenvironment.
\end{abstract}

British Journal of Cancer (201I) I 05, 523-533. doi:I0.1038/bjc.201।.263 www.bjcancer.com

Published online 26 July 2011

(c) 201 I Cancer Research UK

Keywords: ErbB3; EGFR; pancreatic cancer; ErbB3 antibody; tumourigenesis

Pancreatic ductal adenocarcinoma (PDAC) is histologically characterised by an expansive, dense fibrotic reaction known as desmoplasia. This tumour-associated stroma surrounds the ductal adenocarcinoma cells and is composed of extracellular matrix proteins, fibroblasts and stellate cells, adipocytes, endothelial and immune cells. Although a desmoplastic reaction is found in other epithelial tumours, the stromal exuberance associated with PDAC is unique. After being overlooked for years, recent evidence suggests that this desmoplasia may actively support carcinoma cells by providing a reactive microenvironment that dynamically secretes growth factors and cytokines, inhibits tumour cell apoptosis and promotes resistance to therapeutic agents (Mahadevan and Von Hoff, 2007; Bachem et al, 2008; Hwang et al, 2008).

The epidermal growth factor receptor (EGFR) signal transduction system and its associated cell-surface receptors is one of the most studied tyrosine kinase signalling networks in cancer. Epidermal growth factor receptor overexpression has been demonstrated in a wide range of epithelial malignancies, and in many of these tumours, has been shown to correlate with poor prognosis (Modjtahedi and Essapen, 2009). It has been thoroughly

*Correspondence: Dr JP Arnoletti; E-mail: pablo.arnoletti@ccc.uab.edu Revised 17 June 2011; accepted 21 June 2011; published online 26 July 2011 demonstrated in vivo that activation of this receptor family in malignant cells results in reduced apoptosis and increased proliferation, motility, invasion and metastasis. Several anti-EGFR agents, including monoclonal antibodies and small molecule tyrosine kinase inhibitors have been approved by the US Food and Drug Administration for the treatment of patients with advanced epithelial tumours, including non-small-cell lung cancer (NSCLC), colorectal, head and neck, pancreatic and breast cancer (Modjtahedi and Essapen, 2009).

In the case of PDAC, results from in vitro and animal experiments showed much promise for EGFR-targeting agents, but clinical trials have demonstrated modest improvement in overall patient survival (Moore et al, 2007). Subset analysis has shown, however, that patients who develop skin rash seem to obtain the greatest benefit from this type of treatment supporting a role for therapeutic strategies based on anti-EGFR agents in PDAC (Wacker et al, 2007). Carefully designed clinical studies have yet to reliably identify those patients who are more likely to have a favourable response as the underlying mechanisms of resistance remain poorly understood.

We have previously demonstrated that ErbB3, a member of the EGFR family of receptor tyrosine kinases, has a pivotal role in pancreatic tumourigenesis through heterodimerisation with EGFR and induction of phosphoinositide 3-kinase (PI3K)/AKT signalling, which promotes in vitro and in vivo cancer cell proliferation 
(Liles et al, 2010). The role of ErbB3 as a highly specialised activator of other ErbB receptors has only recently been acknowledged. The ErbB3 cell-surface receptor, historically overlooked due to its perceived lack of catalytic activity, has been thought to be inert, functioning only as a scaffolding partner for other more active receptors. It is now known that ErbB3 contains a kinase domain which, when exposed, binds to other ErbB receptors resulting in their activation (Zhang et al, 2006; Jura et al, 2009). Additional findings from our laboratory also point to the lack of activating mutations in EGFR and $E r b B 3$ genes, giving further strength to ligand-driven tumour cell proliferation as a paramount tumourigenic mechanism within the PDAC microenvironment (Tzeng et al, 2007a). Current progress in understanding the important role of ErbB3 has sparked the development of clinical anti-ErbB3 agents. In this study we used MM-121, a fully humanised anti-ErbB3 antibody currently under clinical development, which has been shown to be active in other tumour types.

The purpose of our study was to analyse the role of cancerassociated stroma in PDAC progression while delineating the effects of targeted ErbB3 inhibition in combination with anti-EGFR therapy. We intended to better characterise stromally secreted ligands that induce ErbB signalling in the neighbouring pancreatic carcinoma cells. We hypothesised that cancer-associated fibroblasts (CAF) secrete NRG-1 ligand, which in turn activates cancer cell ErbB3/AKT-mediated signalling, promoting tumourigenesis and rendering EGFR inhibition ineffective. Finally, we wanted to determine if targeted ErbB3 inhibition could effectively prevent tumour cell proliferation and downstream signalling in PDAC.

\section{MATERIALS AND METHODS}

\section{Reagents}

Erlotinib (generously provided by OSI Pharmaceutical Inc., Melville, NY, USA) was dissolved in DMSO to prepare a $20-\mathrm{mM}$ stock solution. MM-121 (generously provided by Merrimack Pharmaceutical, Cambridge, MA, USA) was dissolved directly in the medium to achieve a final concentration of $250 \mu \mathrm{g} \mathrm{ml}^{-1}$. Epidermal growth factor $\left(1 \mathrm{mg} \mathrm{ml}^{-1}\right)$ and heregulin- $\beta 1$, EGF-like domain (neuregulin- $\beta 1 ; 1 \mathrm{mg} \mathrm{ml}^{-1}$ ) were purchased from Sigma (St Louis, MO, USA). ErbB3 blocking/receptor neutralising peptide (clone H3.105.5, Millipore, Temecula, CA, USA) was added directly to the medium to achieve a final concentration of $10 \mu \mathrm{g} \mathrm{ml}^{-1}$. AntiNRG-1 antibody (sc-1793, Santa Cruz Biotechnology, Santa Cruz, CA, USA) was added directly to the medium to achieve a final concentration of $50 \mu \mathrm{g} \mathrm{ml}^{-1}$. Drug concentrations used for in vitro and in vivo studies were based on published data, communications with the manufacturers and our previous work (Jimeno et al, 2006; Frolov et al, 2007; Schoeberl et al, 2010).

\section{Cell culture}

All cell lines were propagated in a humidified atmosphere containing $5 \% \mathrm{CO}_{2}$ at $37^{\circ} \mathrm{C}$. Pancreatic cancer cell lines were purchased from the American Type Culture Collection (Rockville, $\mathrm{MD}$, USA) and propagated according to the provider's recommendations. S2VP10 cells were generously provided by Dr Michael Hollingsworth (University of Nebraska).

\section{Proliferation assay}

Cells were seeded in 96 -well plates $\left(1.5 \times 10^{3}\right.$ cells per well), allowed to propagate overnight before treatment with erlotinib $(5 \mu \mathrm{M})$ or MM-121 $\left(250 \mu \mathrm{g} \mathrm{ml}^{-1}\right.$, suggested by the Merrimack) and stimulated with either EGF $\left(0.1 \mu \mathrm{g} \mathrm{ml}^{-1}\right)$ or NRG-1 $\beta\left(0.22 \mu \mathrm{g} \mathrm{ml}^{-1}\right)$. CellTiter 96 AQueous One Solution Cell Proliferation Assay (Promega, Madison, WI, USA) was used to assess absolute proliferation in cell lines or relative proliferation defined as a ratio between the proliferation of the control untreated cells and drug-treated cells.

\section{Pancreatic cancer patient specimens and laser-capture microdissection}

After Institutional Review Board (IRB)-approved informed consent was obtained, tumour specimens were collected from PDAC patients who underwent surgical treatment under the guidelines of the Surgical Oncology Tumor Bank. Specimens were snap frozen at the time of operation and stored at $-80^{\circ} \mathrm{C}$. Laser-capture microdissection (LCM) was performed as previously described (Tzeng et al, 2007a). An expert pancreatic pathologist (PK) evaluated each specimen and identified regions of adenocarcinoma cells and stromal cells before dissection. Approximately 3000 tumour cells were captured from each specimen for analysis.

\section{RNA extraction and reverse transcriptase PCR}

RNA from microdissected patient specimens was isolated and converted to cDNA as previously described (Liles et al, 2010). Quantitative real-time PCR was performed using TaqMan Gene Expression EGFR, ErbB3,EGF, TGF- $\alpha, N R G-1 \alpha, N R G-1 \beta$ and $R P L P O$ (housekeeping gene) Assays-on-Demand and TaqMan Universal PCR Master Mix in an ABI Prism 7700 Detection System (Applied Biosystems, Carlsbad, CA, USA). Reverse transcriptase PCR (RT-PCR) data are the average of triplicate experiments and represent expression value relative to $R P L P O$ expression in the same specimen.

\section{Western blotting}

Protein lysates were prepared from cell lines or pulverised frozen tumours and standard SDS-PAGE, western blotting and chemiluminescence were performed as previously described (Frolov et al, 2007). The following antibodies were obtained from Millipore: anti-pEGFR tyr845 and anti-pEGFR tyr1173; Sigma: anti- $\beta$-actin and anti-EGFR; Cell Signaling (Beverly, MA, USA): anti-pEGFR tyr992, anti-pEGFR tyr1068, anti-pErbB3 tyr1289, anti-ErbB3, anti-pAKT ser473, anti-AKT, anti-pp44/42 MAPK thr202/tyr204 and anti-MAPK. All antibodies were used as specified by the manufacturer and diluted in 5\% milk. Western blot quantification was performed using ImageJ software package $(\mathrm{NIH}$, Bethesda, MD, USA) according to the developer's instructions.

\section{Primary fibroblast cultures}

Human PDAC specimens were obtained in the operating room as part of patient treatment protocols at our institution and tumour sections were collected under the guidelines of an IRB-approved protocol. Specimens were minced and allowed to incubate in serum-supplemented media (10\% FBS in RPMI media) for 48-72 h, after which time, media was replaced and CAF were collected. Fibroblasts were further propagated in DMEM/F12 media supplemented with $20 \%$ FBS. Cancer-associated fibroblasts used in the in vivo model were immortalised by hTERT expression. Full-length hTERT in a pGIPZ expression vector was obtained from Thermo Fisher Scientific (Pittsburgh, PA, USA).

\section{Primary fibroblasts conditioned media}

Primary fibroblast cultures were grown to $70 \%$ confluence. Culture media was replaced with serum-free media and was incubated with cells for an additional $48 \mathrm{~h}$. Cell-conditioned media was then collected, filtered and concentrated using either 3 or $30 \mathrm{kDa}$ cutoff bioseparation devices (Millipore). Cell-conditioned media was analysed immediately and no freeze-thaw cycles were allowed. 


\section{Immunohistochemistry}

Cells were grown on cover slips as described above. Cover slips were then fixed and stained for cytokeratin-5, cytokeratin-8, pErbB3, epithelial membrane antigen (EMA), $\alpha$-smooth muscle actin ( $\alpha$-SMA), desmin and vimentin at the UAB Clinical Pathology core facility using standard immunohisotchemistry techniques. Stained slides with appropriate negative and positive controls were reviewed by an expert cytopathologist (PK). For xenografts, serial $5 \mu \mathrm{m}$ sections were cut 1 day before immunostaining from the representative formalin-fixed and paraffin-embedded blocks and mounted on Superfrost/Plus slides (Fisher Scientific). Sections were then incubated overnight with primary monoclonal antibodies for pErbB3 and $\alpha$-SMA (Santa Cruz Biotechnology). Secondary detection was performed using a multi-species detection system (Signet Lab Inc., Dedham, MA, USA). Sections were incubated in biotinylated anti-mouse antibodies for $20 \mathrm{~min}$, followed by peroxidase-labelled streptavidin for $20 \mathrm{~min}$ (Signet Lab Inc.). Antigen-antibody complexes were visualised by incubation with 3,3'-diaminobenzidine substrate (BioGenex, San Ramon, CA, USA) and counterstained with diluted Harris haematoxylin. The stained slides were systematically evaluated by a pathologist. The scoring for $\alpha$-SMA was performed by estimating the fraction of positive cells by cell number $(0-100 \%)$, and comparing spindle $v s$ epithelial cell morphology. The pErbB3 scoring was performed by estimating the fraction of positive epithelial cells only, and multiplying by an arbitrary, discrete intensity scale where 0 is negative, and 3 is strongest positive. All negative control slides (omitted primary antibodies) were negative for staining.

\section{Murine xenografts}

Six-week-old female in-bred Fox Chase SCID mice were obtained from Charles River Laboratories (Hartford, CT, USA). Animals were handled according to a protocol approved by the Institutional Animal Care and Use Committee at our university. Mice were allowed to acclimate to animal housing, and xenografts were developed by subcutaneously injecting $5 \times 10^{6}$ AsPC- 1 cells with or without primary fibroblasts $\left(5 \times 10^{6}\right.$ cells for $1: 1 \mathrm{CAF}-\mathrm{AsPC}-1$ cell ratio and $1 \times 10^{7}$ cells for $2: 1 \mathrm{CAF}-\mathrm{AsPC}-1$ cell ratio) to the murine flank bilaterally. Trice weekly, tumour volume was determined using digital caliper measurements and the formula:

$$
\frac{\text { large diameter }{ }^{2} \times \text { small diameter }}{2} \text {. }
$$

After 14 days, all mice had measurable tumours and were sorted into treatment and control groups with equal number of animals $(n=5)$. Treatment group mice received $50 \mathrm{mg} \mathrm{kg}^{-1}$ erlotinib dissolved in vehicle $(0.1 \mathrm{M} \mathrm{NaCl}, 0.05 \%$ pluronic acid in PBS) per treatment while control mice received vehicle only. All mice received 10 intraperitoneal injections over a 14-day period (cycle: five treatment days followed by two non-treatment days). After 14 days, mice were killed.

\section{Statistical analysis}

Correlations between mRNA levels were compared by MannWhitney rank test or two-tailed $t$-test employing SPSS software (Chicago, IL, USA). All cell assay conditions were performed in six wells and repeated in triplicate independent runs and data are presented as mean \pm s.e.m. In these assays, Student's $t$-test was used for comparison and the Mann-Whitney $U$-test was used to compare independent runs. Rate of in vivo tumour growth for a replicate was calculated as a slope of regression line fitted to data representing tumour volume vs seven time points of treatment. Mean rate for a group was calculated as an average of all rates for the group. Rates between any two groups were compared using paired two-tailed $t$-test. Statistical significance level was set at $P$-value $<0.05$.

\section{RESULTS}

\section{NRG-1 is preferentially expressed in the PDAC stromal fibroblast compartment}

We used LCM of surgically resected pancreatic cancer specimens $(n=42)$ to selectively isolate PDAC cells and their surrounding $\mathrm{CAF}$ and to characterise their respective contributions to ligandinduced ErbB signalling within the PDAC microenvironment. We analysed mRNA transcript expression levels of EGFR ligands ( $E G F$ and TGF- $\alpha$ ) and two isoforms of the ErbB3 ligand, NRG-1 (NRG-1 $\alpha$ and $N R G-1 \beta)$ in each one of those two tumour compartments (Figure 1A). TGF- $\alpha$ expression was significantly higher in the ductal adenocarcinoma cells than in CAF $(P=0.005)$, and EGF was equally expressed by both stroma and epithelial cancer cells. Conversely, the two isoforms of NRG-1 were expressed at significantly higher levels in the stromal CAF (NRG-1 $\alpha, P=0.03$; $N R G-1 \beta, P=0.002)$. Interestingly, $N R G-1 \beta$ expression was $2-3$ times greater in the stromal fibroblast compartment when compared with carcinoma cells, suggesting that this ligand is preferentially produced in the stroma and exerts paracrine activity on carcinoma cells.

\section{Establishment of primary fibroblast cultures and analysis of ErbB ligand expression}

To further characterise stromal sources of ErbB ligands, we established primary CAF cultures from fresh human pancreatic cancer specimens $(n=23)$. Although the morphological appearance of the isolated CAF indicated they were fibroblasts, immunohistochemical analysis was performed for lineage verification. Cultured primary CAF (two representative cell lines, CAF-1 and CAF-4, were employed in this experiment) expressed desmin, $\alpha$-SMA and vimentin, which confirmed their mesenchymal lineage (Figure 1B) and clearly distinguished them from epithelial pancreatic cancer cell lines (PANC-1 and BxPC-3), which display cytokeratin and EMA. Expression of vimentin by some pancreatic carcinoma cells results from underlying epithelial-to-mesenchymal transition, a phenomenon previously described in this type of tumour cell (Buck et al, 2007).

In addition, fibroblasts from different tissue sources $(n=9)$ including normal pancreas, normal dermis, chronic pancreatitis, gastrointestinal stromal tumour, pheochromocytoma and colon carcinoma were isolated. RNA was extracted and pooled with the intent of comparing levels of ErbB ligand and ErbB receptor expression to those of pancreatic CAF. Analysis of mRNA transcript levels in these cells demonstrated that fibroblasts are distinctly different in their expression of ErbB ligands based on their tissue of origin. We found significantly higher levels of $N R G-1 \alpha$ and $N R G-1 \beta$ mRNA expression in pancreatic CAF ( $P=0.05$ and $P=0.02$, respectively) relative to all other isolated fibroblasts (Figure 1C). Interestingly, ErbB receptor expression (EGFR and ErbB3 mRNA transcript levels) was not significantly different among the different types of analysed fibroblasts (data not shown).

\section{CAF-conditioned media contains NRG-1 and induces AKT signalling and cellular proliferation in vitro}

To evaluate the postulated paracrine signalling mechanism of CAF on tumour cell growth, we collected serum-free CAF cellconditioned media (CAF-CM). The CAF-CM was selectively filtered with a $3-\mathrm{kDa}$ and a $30-\mathrm{kDa}$ cutoff filter in order to concentrate the media and remove debris. Western blot analysis of CAF-CM confirmed expression of NRG-1 in both the 3- and 
A

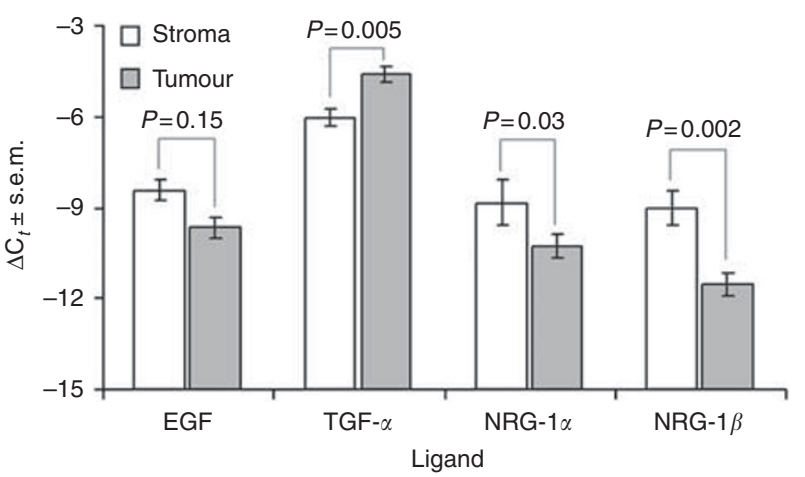

C

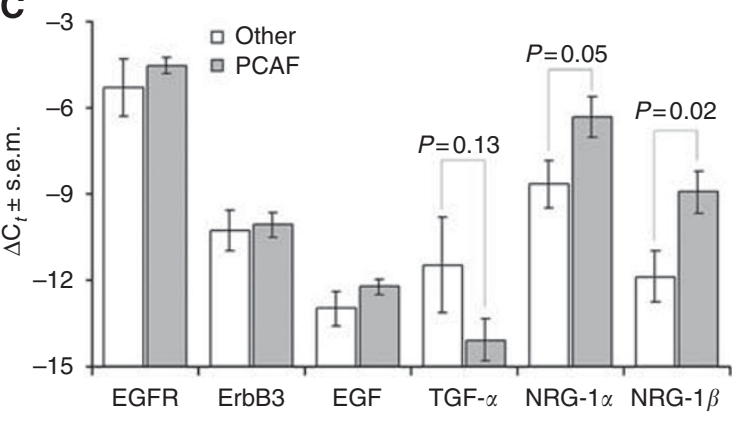

B

PANC-1

Pancreatic adencarcinoma cells

\section{BxPC-3 \\ Pancreatic adencarcinoma cells}

\section{CAF-1 \\ CAF-4}
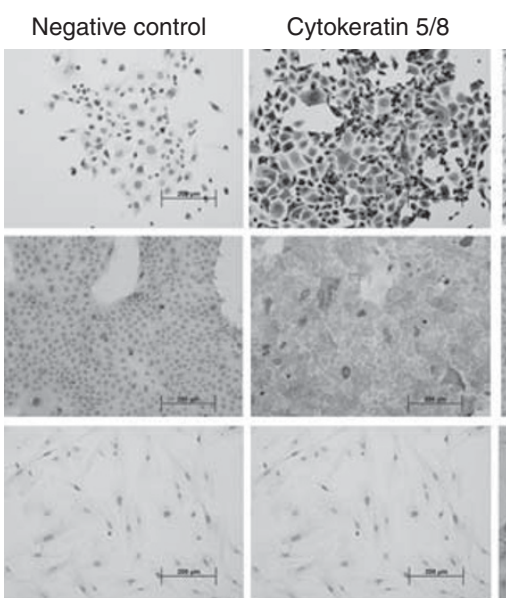
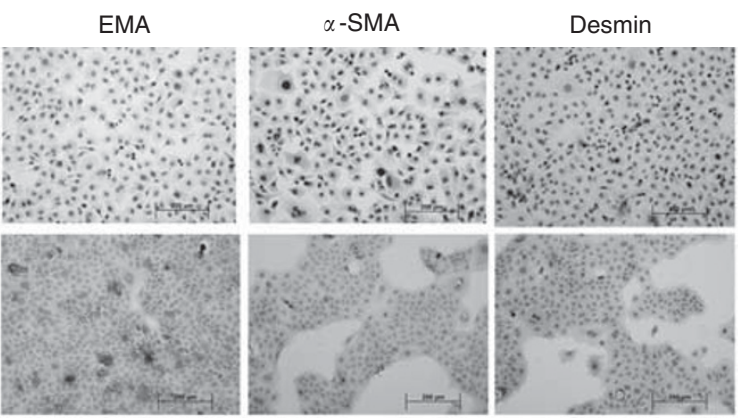

Vimentin
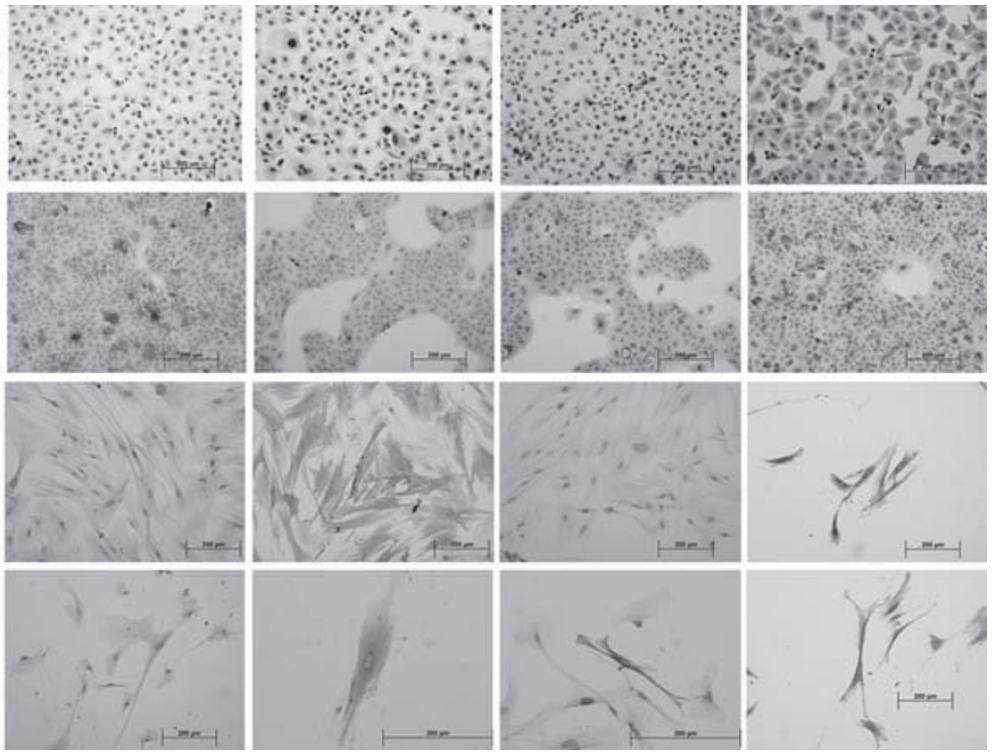

Figure I (A) Ligand expression differences between stroma and tumour in microdissected pancreatic cancer samples. $\Delta C_{t}$ values were calculated as a difference between the target gene $C_{t}$ and RPLPO (housekeeping gene) $C_{t}$ values $\left(C_{t}=\right.$ threshold cycle). Bars represent mean values \pm s.e.m. $P=P$-value for Mann-Whitney rank test. (B) IHC analysis of two primary CAF cultures CAF-I and CAF-4 together with Panc-I and BxPC-3 cell lines. (C) Gene expression differences between $C A F$ and normal tissue fibroblasts. $\Delta C_{t}$ values are calculated against RPLPO $C_{t}$ values. Bars represent mean values \pm s.e.m. $P=P$-value for two-tailed $t$-test.

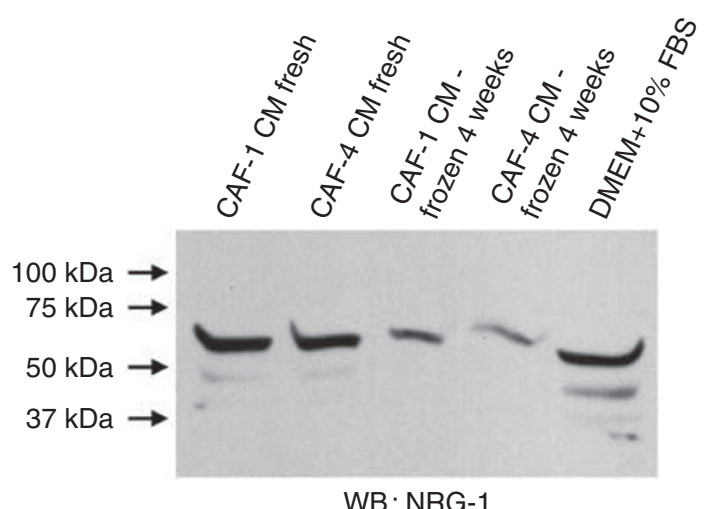

Figure 2 Western blot analysis of NRG-I secretion into CAFconditioned media filtered with $30 \mathrm{kDa}$ cutoff filter (both fresh and after a single freeze-thaw cycle).

30-kDa filtered CAF-CM. We also demonstrated that NRG-1 deteriorates with freeze-thaw cycles, therefore, requiring fresh CAF-CM for all experiments (Figure 2). Stimulation of AsPC-1 cells with CAF-CM resulted in phosphorylation of ErbB3 and AKT, and this intracellular signalling effect was prevented by blocking the receptor with an ErbB3-binding/receptor neutralising peptide (Figure 3). CAF-CM promoted pancreatic cancer cell proliferation in vitro and this effect was moderately diminished by a presence of the inhibitory NRG-1 antibody $(P<0.01)$ (Figure 3 ). The modest effect of the inhibitory NRG-1 antibody could be explained by a modest binding ability of the antibody as well as ongoing proliferation promotion exerted by additional cytokines in the CAF-CM. Nevertheless, our findings confirm without a doubt the presence of CAF-secreted NRG-1 and the stimulatory effects of this ligand on ErbB3 signalling and proliferation of pancreatic cancer cells, further supporting the hypothesis of active stromalepithelial interaction in PDAC.

\section{NRG-1 $\beta$ rescues pancreatic cancer cells from erlotinib inhibition in vitro}

To further investigate the potential influence of ErbB ligands on response to EGFR-targeted therapy, we treated seven PDAC cell lines with erlotinib followed by ligand stimulation with EGF and/or NRG-1 $\beta$. We have previously demonstrated that four of these cell lines all express high levels of EGFR protein while HPAC, 

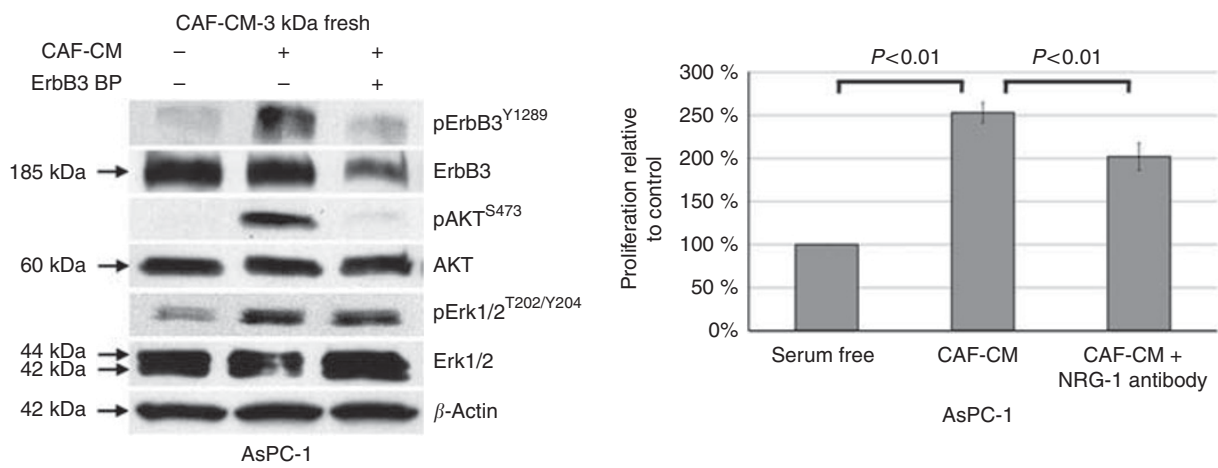

Figure 3 Western blot and proliferation analysis of CAF-conditioned media effects on AsPC-I cells. Addition of ErbB3 blocking peptide or anti-NRG- I neutralising antibody partially abrogates the stimulating effect of CAF-CM.

A

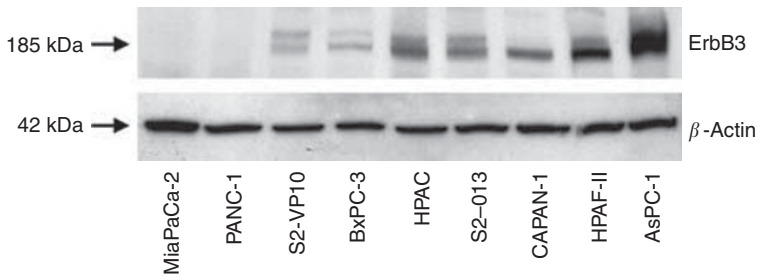

Low ErbB3 expression

Stimulated with NRG-1 $\beta$ after erlotinib treatment

B

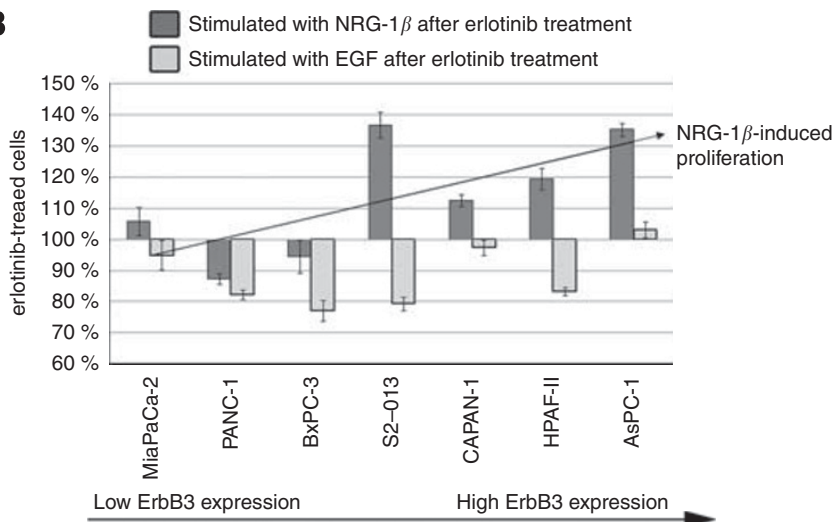

Figure 4 NRG-I $\beta$ abrogates the inhibitory effect of erlotinib in vitro. (A) ErbB3 expression analysis of nine representative pancreatic cell lines. (B) Relative proliferation of nine pancreatic cell lines treated with erlotinib with subsequent stimulation with either EGF or NRG-I $\beta$. Proliferation of the erlotinib-treated control cells is set at 1.0 on the $y$ axis.

MiaPaCa-2 and CAPAN-1 express intermediate amounts of EGFR. We have also described the individual sensitivity of each cell line to erlotinib, with Panc-1 and MiaPaCa-2 cells, displaying resistance to the anti-proliferative effects of the drug (Frolov et al, 2007). Western blot analysis revealed variable baseline ErbB3 protein expression levels in the analysed cell lines (Figure 4A). Pancreatic ductal adenocarcinoma cells that display relatively high expression of ErbB3 (S2-013, CAPAN-1, HPAF-II and AsPC-1), overcome erlotinib-induced growth inhibition when exposed to NRG-1 $\beta$ (Figure 4B). Of interest, NRG-1 $\beta$ failed to stimulate proliferation in the three cell lines with undetectable or very low ErbB3 protein expression (MiaPaCa-2, PANC-1 and BxPC-3). As expected, baseline levels of pancreatic cancer cell EGFR protein did not correlate with the extent of erlotinib-induced growth inhibition.

In an attempt to replicate the effects of exogenously added NRG-1, AsPC-1 PDAC cells were treated with erlotinib in the presence of CAF-CM. The erlotinib-induced inhibitory effect was completely abrogated when AsPC-1 cells were exposed to CAF-CM. As described above, CAF-CM contains NRG-1 and its effects closely resemble those of exogenous NRG-1. This fact was further confirmed when the protective effect of CAF-CM was partially blocked by pre-incubating the CAF-CM with an inhibitory NRG-1 antibody (Figure 5). In other words, CAF-secreted NRG-1 reverted the inhibitory effects of erlotinib on PDAC cell proliferation, suggesting a NRG-1-mediated escape mechanism. We attributed the modest growth inhibition seen with erlotinib in this case to the serum-free conditions of the experiment.

\section{CAF promote pancreatic cancer tumourigenesis}

We generated CAF-containing AsPC-1 xenografts to determine the effects of CAF on pancreatic cancer tumourigenesis. Analysis of human PDAC specimens determined that the ratio of stromal fibroblasts to carcinoma cells ranges from 2:1 to $1: 1$ (data not shown, Dr Andra Frost, personal communication). Therefore, similar ratios of CAF to AsPC-1 cells were employed for our xenografts experiments. After a 4-week interval after injection, higher CAF:AsPC-1 cell ratio directly correlated with greater tumour volume $(P<0.001)$ (Figure 6$)$. Xenografts with a $2: 1$ ratio of CAF:AsPC-1 had a significantly greater average tumour volume than xenografts with a $1: 1$ ratio and a $0: 1$ ratio $(P<0.01)$. The possibility of CAF-induced tumourigenesis in the absence of carcinoma cells was ruled out by the absence of tumour development in a control group of animals inoculated with CAF only.

\section{CAF promote resistance to erlotinib therapy in vivo}

Using the CAF:AsPC-1 xenograft model described above, we analysed the influence of CAF exert on xenograft response to antiEGFR therapy with erlotinib, replicating our in vitro experiment design. As described, on day 13 after tumour inoculation, 2:1 CAF:AsPC-1 xenografts reached a larger size than their counterparts, which contained AsPC-1 cells alone $\left(221\right.$ and $81 \mathrm{~mm}^{3}$, respectively, $P=2 \times 10^{-7}$ ) (Figure $7 \mathrm{~A}$ ). Erlotinib significantly inhibited tumour growth in both CAF:AsPC-1 and AsPC-1 xenografts, but the degree of inhibition was significantly less pronounced in the CAF-containing xenografts $(P=0.008)$ (Figure 7B). CAF:AsPC-1 xenografts remained twice as large as AsPC-1 tumours, indicating an association between the presence of CAF and resistance to erlotinib therapy in vivo. After completion of treatment, animals were killed and xenografts were harvested. Protein analysis of AKT activation was performed in eight tumours from each animal treatment group (Figure 7C). We performed quantification of the immunoblots and normalised pAKT intensities to $\beta$-actin levels for each tumour. As expected, AKT phosphorylation levels in AsPC-1 xenografts were much lower than in CAF:AsPC-1 tumours (2298 average intensity vs 9641, 


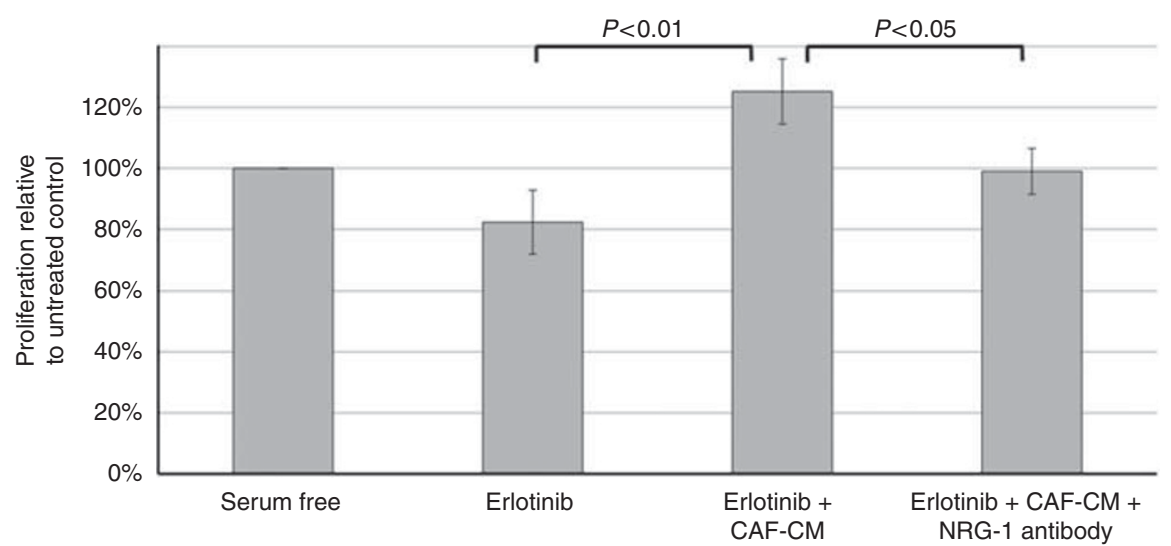

Figure 5 Addition of neutralising NRG-I Ab limits proliferative escape from erlotinib-induced inhibition in the presence of CAF-conditioned media.

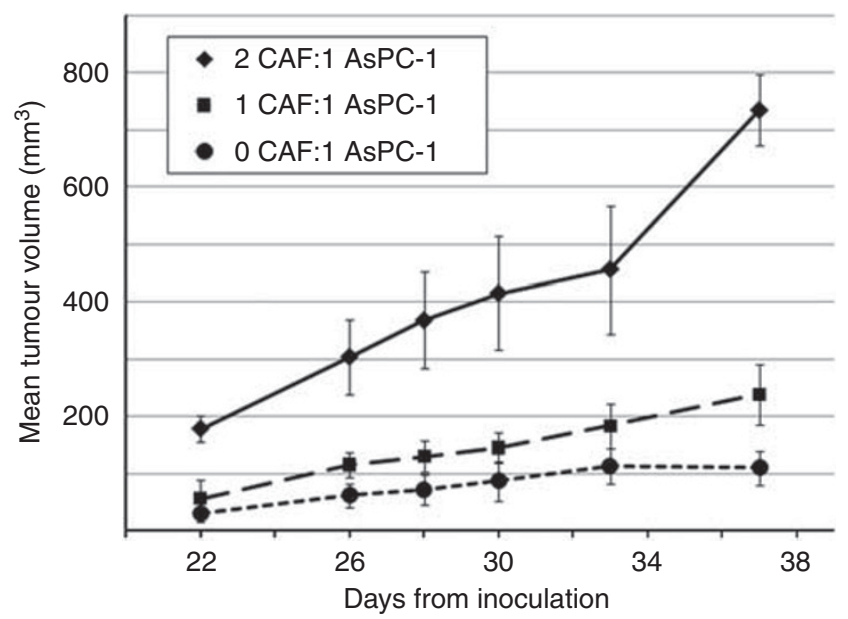

Figure 6 AsPC-I tumour growth without CAF (O) and with CAF at I: I ratio ( $\mathbf{\square})$ and $1: 2$ ratio $(\mathbf{\Lambda})$.

respectively). These findings confirm that larger tumour sizes in the CAF-containing group are due, at least in part, to increased AKT signalling, further supporting active cross-talk mechanisms between CAF and carcinoma cells. Erlotinib was only able to partially abrogate the activation of AKT with higher levels of residual pAKT in CAF-containing tumours (2929 average intensity vs 2336, respectively).

We also estimated the overall fibroblast content of tumours using $\alpha$-SMA immunohistochemistry. While $\alpha$-SMA does stain additional elements such as murine blood vessels (Figure 8A, arrow), positive spindle cells were readily detected and identified as fibroblasts. Among tumours with admixture of CAF and carcinoma cells, the distribution of $\alpha$-SMA-positive fibroblasts showed a uniform pattern (Figure $8 \mathrm{~B}$ ) as opposed to a 'patchy' pattern for the carcinoma cell only group (Figure $8 \mathrm{~A}$ ), where parts of tumour were almost devoid of fibroblasts. There was no overall difference in the total $\alpha$-SMA-positive cell content between the two types of xenograft. In both cases, epithelial cells appeared morphologically identical without evidence of tumour necrosis. Phosphorylated ErbB3 protein localised to the membrane of carcinoma cells levels with lower expression levels in their cytoplasmic compartment (data not shown). Overall expression of pErbB3 protein remained higher in CAF-containing xenografts, and this pattern persisted following erlotinib treatment (average histoscore of 25 vs 10, CAF:AsPC-1 and AsPC-1 alone xenografts, respectively; Figure $8 \mathrm{C}-\mathrm{E}$ ). Tumour cell-surface localisation was present in contiguous areas of the tumour, often in the midsections between tumour surface and centre. These in vivo findings support the concept that CAF are diffusely present in our xenograft model providing a closer resemblance to the pronounced desmoplastic reaction seen in human PDAC specimens. Cancerassociated fibroblasts thus maintain a close interaction with carcinoma cells promoting PI3K/AKT signalling while contributing to an 'escape' mechanism from the effects of erlotinib in PDAC.

\section{MM-121 inhibits proliferation in vitro and in vivo and disrupts PI3K/AKT signalling}

We used a clinical grade ErbB3 Ab inhibitor (MM-121) to effectively halt AsPC-1 proliferation and ErbB3 downstream signalling in vitro (Figure 9). Pretreatment with MM-121 followed by NRG-1 stimulation rendered ligand-induced ErbB3 activation ineffective and combination of MM-121 with erlotinib completely abolished AKT activation in pancreatic cancer cells (Figure 9A). MM-121 also significantly decreased proliferation of AsPC-1 cells in vitro displaying an additive effect with the anti-proliferative properties of erlotinib (Figure 9B). In vivo, MM-121 effectively inhibited tumour growth of AsPC-1 subcutaneous xenografts in a dose-dependent manner. Following tumour harvest, protein analysis of MM-121-treated xenografts revealed marked inhibition of ErbB3 protein activation and expression with the consequent inhibition of AKT phosphorylation (Figure 9C and D).

\section{DISCUSSION}

PDAC remains an extremely aggressive cancer with a dismal clinical outcome. As traditional chemotherapeutic agents have proven to be largely ineffective, the therapeutic focus has shifted to molecular targeted therapy. Epidermal growth factor receptor signalling seems to have an important role in pancreatic cancer tumour progression and EGFR, at least in theory, has been deemed an attractive molecular target for pancreatic cancer treatment (Fjallskog et al, 2003). Growing knowledge suggests, however, that EGFR-mediated tumourigenic mechanisms as well as EGFRtargeted therapeutic approaches are very different for this tumour type when compared with better understood NSCLC or colorectal cancers. The utilisation of both small molecule and mAb antiEGFR agents in combined therapeutic strategies for PDAC has been associated with little or no success (Xiong et al, 2004; Moore et al, 2007; Arnoletti et al, 2011). It has thus become evident that single EGFR inhibition is typically not sufficient to abort critical signalling pathways, as PDAC is not addicted solely to this pathway due to lack of gain-of-function EGFR mutations or EGFR genomic gain (Tzeng et al, 2007a, c). 
A

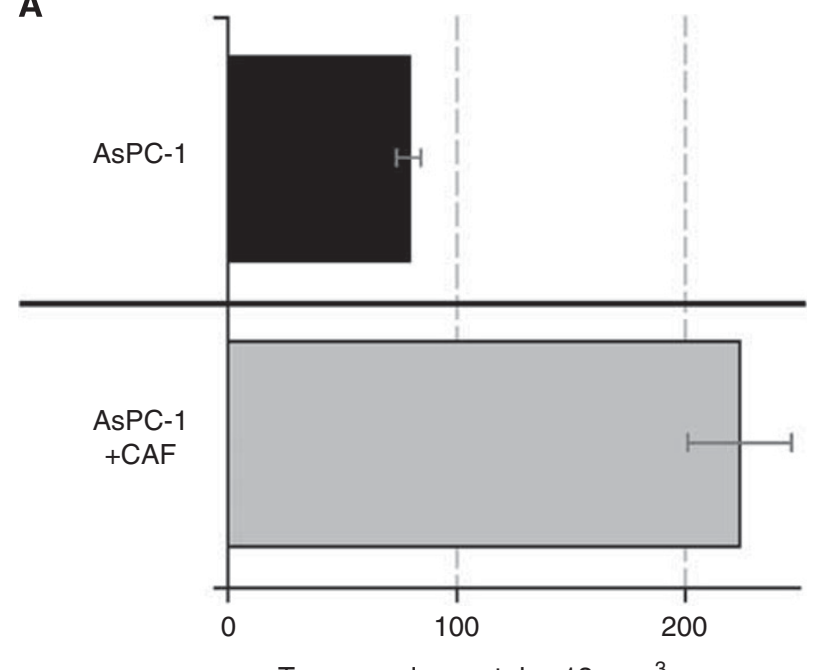

Tumour volume at day $13, \mathrm{~mm}^{3}$

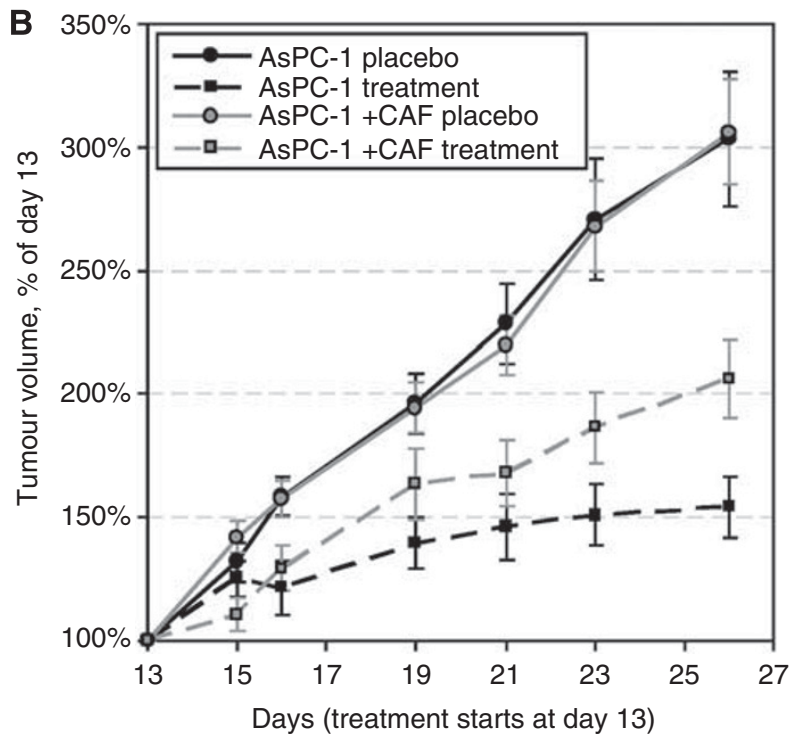

C
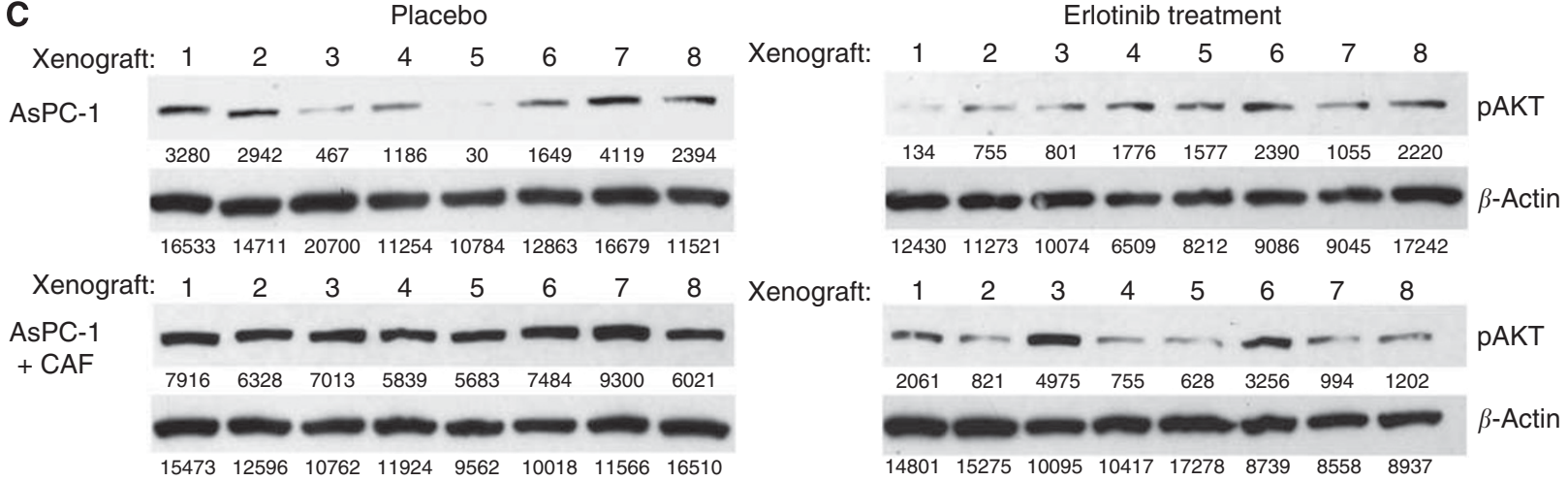

Figure 7 Effects of CAF on tumourigenesis and influence of erlotinib treatment on AKT activation. (A) Tumour volume difference between AsPC-I + CAF and AsPC-I alone xenogratfs on day 13 post-inoculation. (B) Comparison of relative tumour growth between four groups of mice. All data points are represented by mean values with bars showing s.e.m. (C) Western blot analysis of AKT activation in eight representative tumours from each of the four groups of mice. Numbers underneath each lane represent the absolute band intensity.

An alternative explanation for the modest results of EGFR molecular targeting in this type of tumour is the fact that PDAC is a complex, heterogeneous neoplasm that relies on multiple signalling pathways to promote tumour cell proliferation and invasion. One of the suggested mechanisms of resistance involves EGFR-independent activation of downstream signalling. The high incidence of oncogenic KRAS activating mutations found in PDAC ( $90 \%$ of tumours) has been proposed as a contributing factor to the limited effects of EGFR targeting (Almoguera et al, 1988). There is evidence that KRAS mutations are highly specific negative prognostic factors of response (de novo resistance) to EGFRtargeted therapy in both NSCLC and colorectal cancer (Bokemeyer et al, 2009; Jackman et al, 2009). However, a recent meta-analysis has shown low sensitivity and relatively high negative likelihood ratio of KRAS mutations for determining non-responsiveness, clearly showing that additional mechanisms of resistance to EGFR inhibitors exist (Linardou et al, 2008). The true role of KRAS mutations in regards to EGFR therapy for PDAC is yet to be fully discovered and careful cancer-type distinction must be employed as there is little evidence demonstrating true prognostic power of this clinical marker. Data available from the Canadian phase III trial suggest that the predictive nature of KRAS mutations to antiEGFR treatments might not transfer to PDAC (da Cunha Santos et al, 2010). At the present time, it seems premature to dismiss treatment modalities, which include EGFR inhibition based solely on the high incidence of KRAS mutations found in PDAC. A novel approach is needed where a thorough understanding of the underlying mechanisms of resistance is employed to identify new targets for rational combined therapy strategies that may optimise patient selection and clinical results. In that context, we hypothesised that the PDAC stromal component may influence ErbB-mediated signalling with resultant critical effects on tumour cell proliferation and response to EGFR-targeted agents. We understand that this proposed mechanism could be just one of the many plausible scenarios explaining resistance to EGFR-targeted therapies since alternative escape routes such as TGF- $\beta$ and IL-6 axis have been implicated in other tumour types (Yao et al, 2010). We believe, however, that PDAC has distinct biologic features compared with other malignancies, and this uniqueness applies to EGFR/ErbB3 interactions. Here, we present a first attempt to demonstrate the role of combined EGFR/ErbB3 inhibition in the attempt to disrupt stromal-epithelial interactions that promote PDAC cellular proliferation.

A recent consensus report on pancreatic cancer treatment acknowledges and emphasises the need to identify and validate relevant targets in the PDAC microenvironment, including stromal cells (Philip et al, 2009). Given the extent of PDAC desmoplasia, CAF constitute a major component of the tumour-associated stroma and several previous studies have identified these cells as active interactors of carcinoma cells. Cancer-associated fibroblasts 


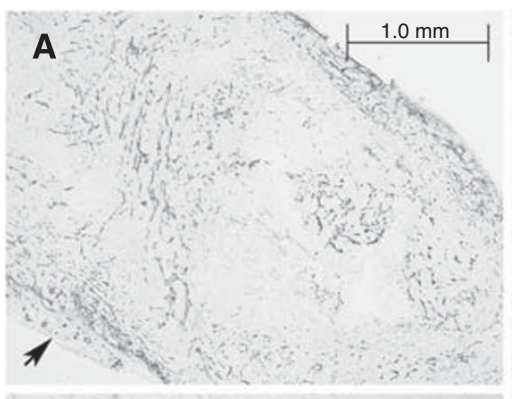

C
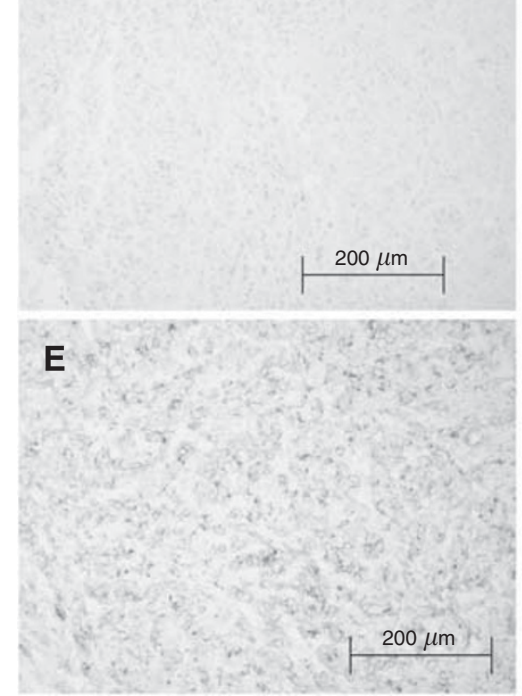

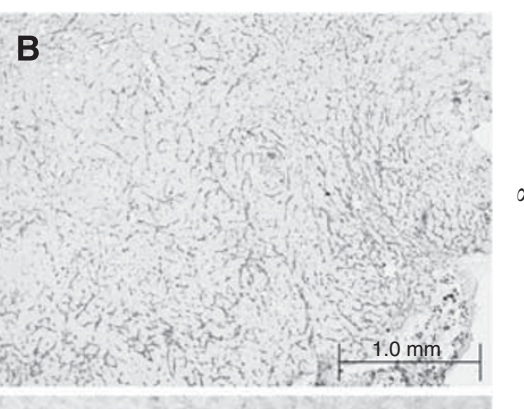

$\alpha$-SMA

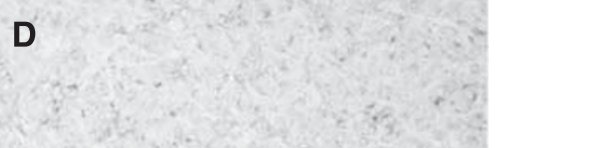

pErbB3

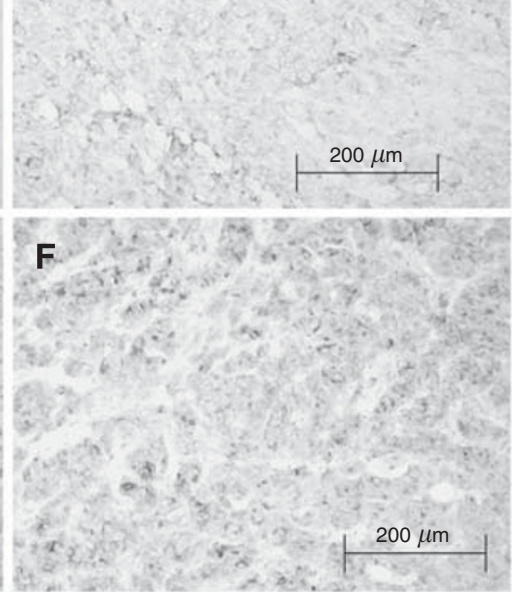

(1)

pErbB3

Figure $8 \mathrm{HC}$ analysis of xenograft tumours with and without CAF and effect of erlotinib treatment. The photographs $(\mathbf{A}, \mathbf{B})$ show low power $(4 \times)$ representative sections of $\alpha$-SMA staining of AsPC-I and AsPC-I + CAF xenografts, respectively. The photographs $(\mathbf{C}, \mathbf{D})$ show representative sections of pErbB3 expression in erlotinib-treated AsPC-I and AsPC-I + CAF xenografts. A high power $(20 \times)$ view demonstrates positive membranous pattern, scored as intensity 2 on a $0-3$ scale $(\mathbf{D})$, the opposite $(\mathbf{C})$ shows negative staining. The photographs $(\mathbf{E}, \mathbf{F})$ show representative sections of pErbB3 staining in placebo-treated AsPC-I and AsPC-I + CAF xenografts.

have been shown to increase in vitro tumour cell proliferation, migration, invasion and colony formation, as well as in vivo tumour size and metastasis (Hwang et al, 2008). In our present study, we have incorporated stromal CAF to our pancreatic cancer xenografts to better model the real-life microenvironment found in human PDAC.

In search of the mechanisms that promote tumourigenic ErbB signalling, we have previously demonstrated that unlike NSCLC, pancreatic cancer cells lack activating EGFR mutations (Tzeng et al, 2007a). EGFR gene amplification, while prevalent in PDAC specimens, has been inconsistently linked with clinical response to EGFR inhibition in other tumour types (Tzeng et al, 2007b; Dahabreh et al, 2010). We, therefore, turned our attention to receptor heterodimerisation and ligand overexpression as plausible mechanisms of aberrant ErbB activation and downstream signalling.

ErbB3 overexpression has been clearly implicated in epithelial cancer progression (Kraus et al, 1989). It was originally felt that since the ErbB3 catalytic domain shows very weak kinase activity if any, ErbB3 was an obligate heterodimerisation partner (Berger et al, 2004). It has been recently demonstrated, however, that ErbB3 not only has kinase activity but its intracellular domain is competent to bind ATP and capable of catalysing auto-phosphorylation, a concept that is still being debated (Shi et al, 2010). NRG-1 as an ErbB3 ligand interacts with the receptor and increases its phosphorylation (Holbro et al, 2003). It has also been shown that the EGF-like domain of NRG-1 binds to domains I and II of
ErbB3 leading to the activation of the receptor (Singer et al, 2001) For downstream signalling, ErbB3 couples with PI3K to activate the AKT signalling cascade (Kim et al, 1994; Soltoff et al, 1994). ErbB3 signalling promotes resistance to tyrosine kinase inhibition in breast cancer cells via heterodimerisation with ErbB2 (Sergina et al, 2007; Schoeberl et al, 2009). There is therefore considerable evidence that points to ErbB3 as a key hub within the cellular ErbB signalling network (Schoeberl et al, 2009).

Our prior findings indicate that pancreatic cancer cells sensitive to EGFR-targeted therapy can be rendered resistant via siRNAinduced ErbB3 inhibition, which suggests a critical influence of ErbB3 in pancreatic cancer EGFR signalling (Frolov et al, 2007). This role has been confirmed by the promotion of tumourigenesis employing stable ErbB3 transfection in the wild-type ErbB3deficient pancreatic cancer cells (Tzeng et al, 2007b). We have also convincingly demonstrated that ErbB3 is the preferential heterodimerisation partner of EGFR in pancreatic cancer cells (Frolov et al, 2007). More importantly, however, ErbB3 is overexpressed in pancreatic cancer (Lemoine et al, 1992; Friess et al, 1995; Kolb et al, 2007) and high expression of ErbB3 correlates with advanced stage and decreased overall survival (Friess et al, 1995). ErbB3 ligands such as NRG-1 are expressed by pancreatic cancer cells and have been linked to pancreatic cancer cell growth and patient survival (Kolb et al, 2007). The influence of ligand expression on response to EGFR-targeted agents has already been described in colorectal cancer (Khambata-Ford et al, 2007; Jacobs et al, 2009). By analogy, and given the presence of EGFR-ErbB3 heterodimers 
A

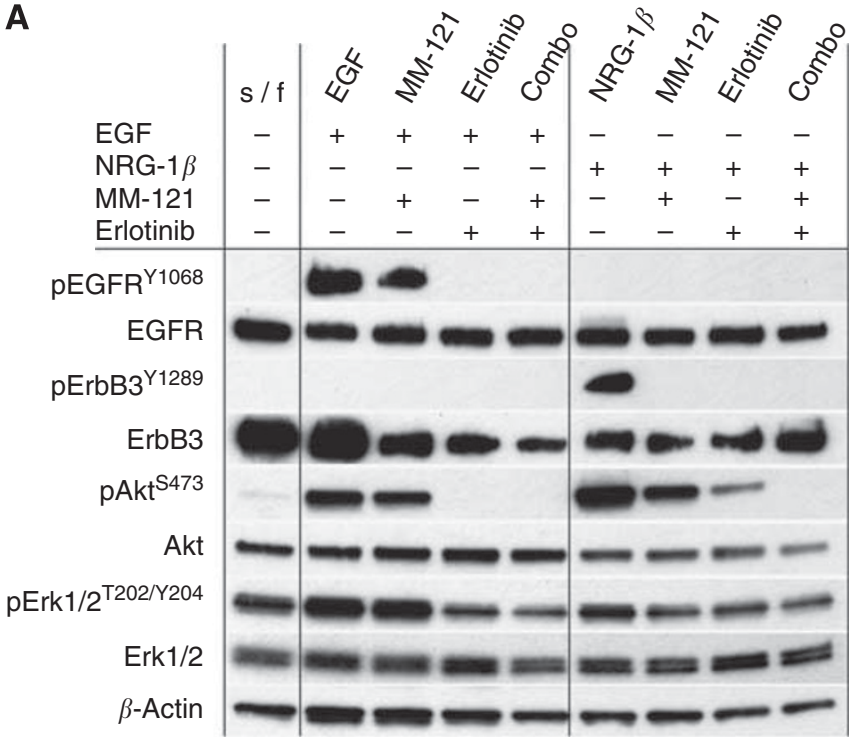

B

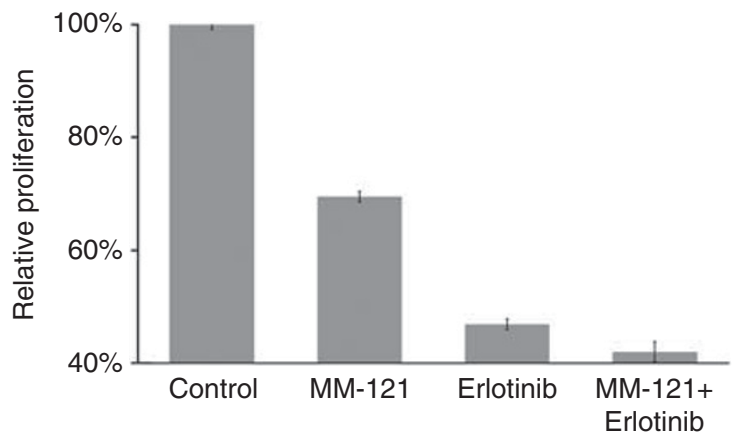

C

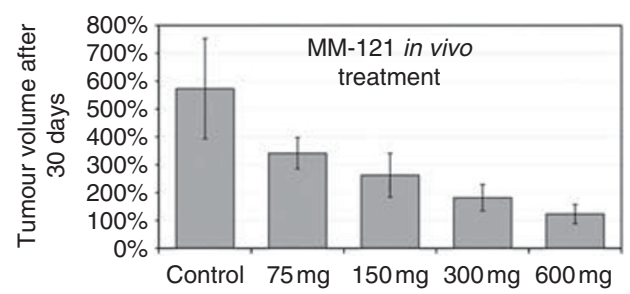

D

\begin{tabular}{|c|c|c|}
\hline & Control & MM-121 \\
\hline pErbB3 & ---- & 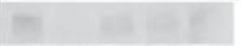 \\
\hline ErbB3 & 을 & $m-m=$ \\
\hline pAKT & ----- & ---- \\
\hline AKT & $=$ & 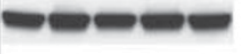 \\
\hline$\beta$-Actin & $-\infty-0=$ & $-\infty-\infty=0$ \\
\hline
\end{tabular}

Figure 9 Effects of MM-I2I ErbB3 antibody on AsPC-I cell proliferation and signalling both in vitro and in vivo. (A) Western blot analysis of inhibitory effect of erlotinib, MM- I2I and their combination following EGF or NRG- I stimulation. (B) Inhibition of AsPC-I proliferation with erlotinib, MM-I2I and their combination. (C) MM- 121 inhibits AsPC-I tumour progression in a dose-dependent manner. (D) Western blot analysis of AsPC-I xenografts depicting the inhibition of ErbB3 activation and expression and inhibition of pAKT.

in pancreatic cancer cells, we postulated that NRG-1, a specific ErbB3 ligand, is secreted by the stroma, forms an active paracrine loop and influences response to EGFR inhibition by erlotinib.
Our current results confirm that pancreatic cancer cell expression of ErbB3 and ErbB3-mediated signalling modulates response to EGFR inhibition. More importantly, aberrant pancreatic cancer ErbB3 signalling is a ligand-driven mechanism supported by CAF from the surrounding stroma as a source of NRG-1. Selective analysis of CAF from PDAC surgical specimens has allowed us to characterise a specific paracrine signalling cascade between stromal cells and carcinoma cells that promotes cancer cell proliferation in vitro and in vivo. We have identified the consistent expression of NRG-1 by CAF in the tumour microenvironment and have thoroughly demonstrated that this ligand promotes tumourigenesis through ErbB3/PI3K/AKT activation. Furthermore, we have demonstrated that CAF secretion of NRG-1 actively circumvents the inhibitory effect of erlotinib and promotes tumour growth providing an 'escape' mechanism to EGFR-targeted therapy. These findings may help explain the modest clinical results of EGFR-targeted therapy and support a role for combined EGFR/ErbB3 targeting in the treatment of advanced pancreatic cancer. They also provide further evidence that pancreatic CAF exhibit unique characteristics that distinguish them from other types of fibroblasts and support a very active stromal role in this dynamic tumour system. NRG-1 ligands are consistently expressed within the PDAC stroma and we propose ligand-driven ErbB signalling as a fundamental mechanism for tumour progression in PDAC. Finally, we have demonstrated for the first time the effectiveness of MM-121, a specific anti-ErbB3 inhibitor, to inhibit proliferation of PDAC cells as well as murine pancreatic cancer xenografts and to disrupt the activation of PI3K/AKT as a critical proliferative pathway.

Our results point to the utility of incorporating stromal elements to PDAC in vivo experimental models in an effort to better model real-life tumour microenvironment conditions. The inclusion of primary CAF in PDAC xenografts allows for dynamic stromalepithelial interactions that beyond doubt exert a powerful influence on therapeutic response to targeted agents.

Despite our focus on ErbB3 ligands, it is highly likely that additional ligands are secreted by the stroma and that both ErbB and non-ErbB pathways are stimulated by that interaction. As mentioned, PDAC is a complex tumour with an array of synchronously activated pathways. Inhibition of ErbB signalling, even when targeting both EGFR and ErbB3, may not be sufficient to effectively halt PDAC tumour progression. Alternative non-ErbB-mediated escape mechanisms may be present or subsequently develop that render this type of approach ineffective. Additional targeted agents or optimal combinations with traditional chemotherapeutic drugs may be, therefore, necessary to achieve better treatment results in this challenging tumour type.

We conclude that stromal CAF-secreted NRG-1 stimulates ErbB3/AKT signalling and promotes pancreatic cancer cell tumourigenesis, providing a mechanism that may contribute to PDAC resistance to anti-EGFR therapy. We propose NRG-1 and ErbB3 as novel molecular targets that may lead to more successful therapeutic modalities for PDAC patients. We also suggest that MM-121 shows great potential in inhibiting PDAC ErbB3 signalling and should be tested in the clinical setting.

\section{ACKNOWLEDGEMENTS}

This study was supported by NIH/NRSA T32 Grant (JSL) and from the Robert E Reed Gastrointestinal Oncology Research Foundation.

\section{Conflict of interest}

The authors declare no conflict of interest. 


\section{REFERENCES}

Almoguera C, Shibata D, Forrester K, Martin J, Arnheim N, Perucho M (1988) Most human carcinomas of the exocrine pancreas contain mutant c-K-ras genes. Cell 53: 549-554

Arnoletti JP, Frolov A, Eloubeidi M, Keene K, Posey J, Wood T, Greeno E, Jhala N, Varadarajulu S, Russo S, Christein J, Oster R, Buchsbaum DJ, Vickers SM (2011) A phase I study evaluating the role of the antiepidermal growth factor receptor (EGFR) antibody cetuximab as a radiosensitizer with chemoradiation for locally advanced pancreatic cancer. Cancer Chemother Pharmacol 67: 891 - 897

Bachem MG, Zhou S, Buck K, Schneiderhan W, Siech M (2008) Pancreatic stellate cells - role in pancreas cancer. Langenbecks Arch Surg 393: $891-900$

Berger MB, Mendrola JM, Lemmon MA (2004) ErbB3/HER3 does not homodimerize upon neuregulin binding at the cell surface. FEBS Lett 569: $332-336$

Bokemeyer C, Bondarenko I, Makhson A, Hartmann JT, Aparicio J, de Braud F, Donea S, Ludwig H, Schuch G, Stroh C, Loos AH, Zubel A, Koralewski P (2009) Fluorouracil, leucovorin, and oxaliplatin with and without cetuximab in the first-line treatment of metastatic colorectal cancer. J Clin Oncol 27: 663-671

Buck E, Eyzaguirre A, Barr S, Thompson S, Sennello R, Young D, Iwata KK, Gibson NW, Cagnoni P, Haley JD (2007) Loss of homotypic cell adhesion by epithelial-mesenchymal transition or mutation limits sensitivity to epidermal growth factor receptor inhibition. Mol Cancer Ther 6: 532-541

da Cunha Santos G, Dhani N, Tu D, Chin K, Ludkovski O, Kamel-Reid S, Squire J, Parulekar W, Moore MJ, Tsao MS (2010) Molecular predictors of outcome in a phase 3 study of gemcitabine and erlotinib therapy in patients with advanced pancreatic cancer: National Cancer Institute of Canada Clinical Trials Group Study PA.3. Cancer 116: 5599-5607

Dahabreh IJ, Linardou H, Siannis F, Kosmidis P, Bafaloukos D, Murray S (2010) Somatic EGFR mutation and gene copy gain as predictive biomarkers for response to tyrosine kinase inhibitors in non-small cell lung cancer. Clin Cancer Res 16: $291-303$

Fjallskog ML, Lejonklou MH, Oberg KE, Eriksson BK, Janson ET (2003) Expression of molecular targets for tyrosine kinase receptor antagonist in malignant endocrine pancreatic tumors. Clin Cancer Res 9: 1469-1473

Friess H, Yamanaka Y, Kobrin MS, Do DA, Buchler MW, Korc M (1995) Enhanced erbB-3 expression in human pancreatic cancer correlates with tumor progression. Clin Cancer Res 1: 1413-1420

Frolov A, Schuller K, Tzeng CW, Cannon EE, Ku BC, Howard JH, Vickers SM, Heslin MJ, Buchsbaum DJ, Arnoletti JP (2007) ErbB3 expression and dimerization with EGFR influence pancreatic cancer cell sensitivity to erlotinib. Cancer Biol Ther 6: 548-554

Holbro T, Beerli RR, Maurer F, Koziczak M, Barbas III CF, Hynes NE (2003) The ErbB2/ErbB3 heterodimer functions as an oncogenic unit: ErbB2 requires ErbB3 to drive breast tumor cell proliferation. Proc Natl Acad Sci USA 100: 8933 - 8938

Hwang RF, Moore T, Arumugam T, Ramachandran V, Amos KD, Rivera A, Ji B, Evans DB, Logsdon CD (2008) Cancer-associated stromal fibroblasts promote pancreatic tumor progression. Cancer Res 68: $918-926$

Jackman DM, Miller VA, Cioffredi LA, Yeap BY, Janne PA, Riely GJ, Ruiz MG, Giaccone G, Sequist LV, Johnson BE (2009) Impact of epidermal growth factor receptor and KRAS mutations on clinical outcomes in previously untreated non-small cell lung cancer patients: results of an online tumor registry of clinical trials. Clin Cancer Res 15: $5267-5273$

Jacobs B, De Roock W, Piessevaux H, Van Oirbeek R, Biesmans B, De Schutter J, Fieuws S, Vandesompele J, Peeters M, Van Laethem JL, Humblet Y, Penault-Llorca F, De Hertogh G, Laurent-Puig P, Van Cutsem E, Tejpar S (2009) Amphiregulin and epiregulin mRNA expression in primary tumors predicts outcome in metastatic colorectal cancer treated with cetuximab. J Clin Oncol 27: 5068-5074

Jimeno A, Kulesza P, Kincaid E, Bouaroud N, Chan A, Forastiere A, Brahmer J, Clark DP, Hidalgo M (2006) C-fos assessment as a marker of anti-epidermal growth factor receptor effect. Cancer Res 66: 2385-2390

Jura N, Shan Y, Cao X, Shaw DE, Kuriyan J (2009) Structural analysis of the catalytically inactive kinase domain of the human EGF receptor 3. Proc Natl Acad Sci USA 106: 21608-21613

Khambata-Ford S, Garrett CR, Meropol NJ, Basik M, Harbison CT, Wu S, Wong TW, Huang $\mathrm{X}$, Takimoto $\mathrm{CH}$, Godwin $\mathrm{AK}$, Tan BR, Krishnamurthi SS, Burris III HA, Poplin EA, Hidalgo M, Baselga J, Clark EA, Mauro DJ (2007) Expression of epiregulin and amphiregulin and K-ras mutation status predict disease control in metastatic colorectal cancer patients treated with cetuximab. J Clin Oncol 25: 3230-3237

Kim HH, Sierke SL, Koland JG (1994) Epidermal growth factor-dependent association of phosphatidylinositol 3-kinase with the erbB3 gene product. J Biol Chem 269: $24747-24755$

Kolb A, Kleeff J, Arnold N, Giese NA, Giese T, Korc M, Friess H (2007) Expression and differential signaling of heregulins in pancreatic cancer cells. Int J Cancer 120: 514-523

Kraus MH, Issing W, Miki T, Popescu NC, Aaronson SA (1989) Isolation and characterization of ERBB3, a third member of the ERBB/epidermal growth factor receptor family: evidence for overexpression in a subset of human mammary tumors. Proc Natl Acad Sci USA 86: 9193-9197

Lemoine NR, Lobresco M, Leung H, Barton C, Hughes CM, Prigent SA, Gullick WJ, Kloppel G (1992) The erbB-3 gene in human pancreatic cancer. J Pathol 168: 269-273

Liles JS, Arnoletti JP, Tzeng CW, Howard JH, Kossenkov AV, Kulesza P, Heslin MJ, Frolov A (2010) ErbB3 expression promotes tumorigenesis in pancreatic adenocarcinoma. Cancer Biol Ther 10: 555-563

Linardou H, Dahabreh IJ, Kanaloupiti D, Siannis F, Bafaloukos D, Kosmidis P, Papadimitriou CA, Murray S (2008) Assessment of somatic k-RAS mutations as a mechanism associated with resistance to EGFR-targeted agents: a systematic review and meta-analysis of studies in advanced non-small-cell lung cancer and metastatic colorectal cancer. Lancet Oncol 9: $962-972$

Mahadevan D, Von Hoff DD (2007) Tumor-stroma interactions in pancreatic ductal adenocarcinoma. Mol Cancer Ther 6: 1186-1197

Modjtahedi H, Essapen S (2009) Epidermal growth factor receptor inhibitors in cancer treatment: advances, challenges and opportunities. Anticancer Drugs 20: $851-855$

Moore MJ, Goldstein D, Hamm J, Figer A, Hecht JR, Gallinger S, Au HJ, Murawa P, Walde D, Wolff RA, Campos D, Lim R, Ding K, Clark G, Voskoglou-Nomikos T, Ptasynski M, Parulekar W (2007) Erlotinib plus gemcitabine compared with gemcitabine alone in patients with advanced pancreatic cancer: a phase III trial of the National Cancer Institute of Canada Clinical Trials Group. J Clin Oncol 25: 1960-1966

Philip PA, Mooney M, Jaffe D, Eckhardt G, Moore M, Meropol N, Emens L, O'Reilly E, Korc M, Ellis L, Benedetti J, Rothenberg M, Willett C, Tempero M, Lowy A, Abbruzzese J, Simeone D, Hingorani S, Berlin J Tepper J (2009) Consensus report of the national cancer institute clinical trials planning meeting on pancreas cancer treatment. J Clin Oncol 27: $5660-5669$

Schoeberl B, Faber AC, Li D, Liang MC, Crosby K, Onsum M, Burenkova O, Pace E, Walton Z, Nie L, Fulgham A, Song Y, Nielsen UB, Engelman JA, Wong KK (2010) An ErbB3 antibody, MM-121, is active in cancers with ligand-dependent activation. Cancer Res 70: 2485-2494

Schoeberl B, Pace EA, Fitzgerald JB, Harms BD, Xu L, Nie L, Linggi B, Kalra A, Paragas V, Bukhalid R, Grantcharova V, Kohli N, West KA Leszczyniecka M, Feldhaus MJ, Kudla AJ, Nielsen UB (2009) Therapeutically targeting ErbB3: a key node in ligand-induced activation of the ErbB receptor-PI3K axis. Sci Signal 2: ra31

Sergina NV, Rausch M, Wang D, Blair J, Hann B, Shokat KM, Moasser MM (2007) Escape from HER-family tyrosine kinase inhibitor therapy by the kinase-inactive HER3. Nature 445: 437-441

Shi F, Telesco SE, Liu Y, Radhakrishnan R, Lemmon MA (2010) ErbB3/ HER3 intracellular domain is competent to bind ATP and catalyze autophosphorylation. Proc Natl Acad Sci USA 107: $7692-7697$

Singer E, Landgraf R, Horan T, Slamon D, Eisenberg D (2001) Identification of a heregulin binding site in HER3 extracellular domain. $J$ Biol Chem 276: 44266 - 44274

Soltoff SP, Carraway III KL, Prigent SA, Gullick WG, Cantley LC (1994) ErbB3 is involved in activation of phosphatidylinositol 3-kinase by epidermal growth factor. Mol Cell Biol 14: 3550-3558

Tzeng CW, Frolov A, Frolova N, Jhala NC, Howard JH, Buchsbaum DJ, Vickers SM, Heslin MJ, Arnoletti JP (2007a) Epidermal growth factor receptor (EGFR) is highly conserved in pancreatic cancer. Surgery 141: $464-469$

Tzeng CW, Frolov A, Frolova N, Jhala NC, Howard JH, Vickers SM, Buchsbaum DJ, Heslin MJ, Arnoletti JP (2007b) EGFR genomic gain and aberrant pathway signaling in pancreatic cancer patients. J Surg Res 143: $20-26$

Tzeng CW, Frolov A, Frolova N, Jhala NC, Howard JH, Vickers SM, Buchsbaum DJ, Heslin MJ, Arnoletti JP (2007c) Pancreatic cancer epidermal growth factor receptor (EGFR) intron 1 polymorphism 
ErbB3 and NRG-I in pancreatic cancer EGFR resistance

JS Liles et al

influences postoperative patient survival and in vitro erlotinib response. Ann Surg Oncol 14: 2150-2158

Wacker B, Nagrani T, Weinberg J, Witt K, Clark G, Cagnoni PJ (2007) Correlation between development of rash and efficacy in patients treated with the epidermal growth factor receptor tyrosine kinase inhibitor erlotinib in two large phase III studies. Clin Cancer Res 13: 3913-3921

Xiong HQ, Rosenberg A, LoBuglio A, Schmidt W, Wolff RA, Deutsch J, Needle M, Abbruzzese JL (2004) Cetuximab, a monoclonal antibody targeting the epidermal growth factor receptor, in combination with gemcitabine for advanced pancreatic cancer: a multicenter phase II Trial. J Clin Oncol 22: 2610-2616

Yao Z, Fenoglio S, Gao DC, Camiolo M, Stiles B, Lindsted T, Schlederer M, Johns C, Altorki N, Mittal V, Kenner L, Sordella R (2010) TGF-beta IL-6 axis mediates selective and adaptive mechanisms of resistance to molecular targeted therapy in lung cancer. Proc Natl Acad Sci USA 107: $15535-15540$

Zhang X, Gureasko J, Shen K, Cole PA, Kuriyan J (2006) An allosteric mechanism for activation of the kinase domain of epidermal growth factor receptor. Cell 125: 1137-1149 